\title{
A Study on Job Satisfaction and Professionalism Perception as Predictors of Childcare Teachers' Intention to Stay
}

\author{
Jiyoung Lee \\ College of Teacher Education, Tarlac State University, Philippines
}

Received June 30, 2020; Revised August 6, 2020; Accepted September 11, 2020

\section{Cite This Paper in the following Citation Styles}

(a): [1] Jiyoung Lee, "A Study on Job Satisfaction and Professionalism Perception as Predictors of Childcare Teachers' Intention to Stay," Universal Journal of Educational Research, Vol. 8, No. 10, pp. 4743 - 4750, 2020. DOI: 10.13189/ujer.2020.081045.

(b): Jiyoung Lee (2020). A Study on Job Satisfaction and Professionalism Perception as Predictors of Childcare Teachers' Intention to Stay. Universal Journal of Educational Research, 8(10), 4743 - 4750. DOI: 10.13189/ujer.2020.081045.

Copyright $\bigcirc 2020$ by authors, all rights reserved. Authors agree that this article remains permanently open access under the terms of the Creative Commons Attribution License 4.0 International License

\begin{abstract}
The intention to stay of childcare teachers is an important factor to be considered in providing quality childcare services. Against this backdrop, the purpose of this study is to investigate the effect of childcare teacher job satisfaction and professionalism perception on a teacher's intention to stay. By examining these variables, this study can help enrich existing studies on teacher education program development. The subject of the study was 280 childcare teachers working in care centers located in Seoul and Gyeonggi-do. A survey was conducted from November 3 to November 25, 2019. 245 collected data were analyzed using SPSS 23.0 by performing reliability coefficient calculation, technical statistics, Pearson correlation analysis, and hierarchical regression analysis. The results of this study are two-fold. First, job satisfaction is positively correlated with professionalism perception and the intention to stay, as professionalism perception is likewise positively correlated with the intention to stay. Second, job satisfaction and professionalism perception have a positive effect on the teachers' intention to stay. Based on these results, this study concludes that the school administration and other stakeholders who are concerned with teacher education development must consider job satisfaction and professionalism in order to increase the intention of childcare teachers to stay.
\end{abstract}

Keywords Childcare Teacher, Job Satisfaction, Professionalism Perception, Intention to Stay, Hierarchical Regression Analysis

\section{Introduction}

Societal interest regarding childcare is due to the decreasing prevalence of child rearing at home. Such is the result of varying socio-economic activities of women, the increasing number of working couples, and the changing family structure. Accordingly, the government continues to expand childcare-related support, thereby reducing the burden of raising children on households and contributing to de-familiarization of childcare [1]. Through the government's support, the number of daycare centers and childcare centers increased. Looking at childcare statistics from the Ministry of Health and Welfare (2019), the number of daycare centers in 2009 was 35,550, and after 10 years in 2018, it increased by 39,171 , recording an increase of $10.1 \%$ [2]. In 2018, it increased by $20 \%$ to $1,415,742$. This quantitative increase in childcare services has led to growing interest in the qualitative development of childcare [3].

Childcare centers provide rearing services in a safe environment that would promote the holistic growth of infants and toddlers, such as social, emotional, and cognitive development [4]. Childcare teachers, who are responsible for childcare and education of young children in daycare, are important in determining the quality of childcare [5]. 
A childcare teacher whose position is stable will be more consistent in delivering high-quality childcare services. In line with this, it is important to consider the intention to stay of the childcare teacher. Intention to stay refers to the resolve of the members of the organization to remain and work in that organization [6]. This has a positive effect on the organization as it increases the morale of employees in the organization and strengthens the organizational commitment to improve the stability of the entire organization [7]. A study shows that early childhood teachers deliver higher quality programs compared to other teachers if they intend to remain in early childhood education for more than 5 years [8]. The study reaffirms the significance of examining the intention of the teachers to stay as a factor that positively affects the quality of the daycare center as well as the organizational commitment of teachers [9]. Since it is crucial for the nursery teacher to play a stable role, parents are demanding that nursery teachers remain in the daycare center without reservations as they care for the infants and toddlers [10]. That is, in order to provide stable and consistently high-quality childcare services, it is necessary to consider the intention to stay of childcare teachers.

Cho, Johanson \& Guchait (2009) argued that perceived low turnover intention acts as an important predictor of the intention to stay [11]. It is then effective to look at the predictive variable of turnovers in order to measure the intention to stay. Variables that affect the intention of the childcare teacher's turnover include organizational culture [12], job satisfaction [13], teacher effectiveness [14], and recognition of professionalism [15].

Environmental factors likewise influence teachers' mental health and their intention to stay [16]. Appel-Drazin (2016) emphasized that early childhood teachers must consider the environment of their work in order to remain and work in early childhood education [17]. Singh \& Billingsley (1996) and Sedivy-Benton \& Boden McGill (2012) also posited that the working environment is a decisive factor in the intention of the teachers to remain [18], [19]. Working satisfaction, which pertains to the contentment with the working environment, is also a predictor of intention to stay, as studies show [20], [21]. The organizational culture, organizational commitment, and job satisfaction are also considered as factors in the working environment related to the residual intention of teachers [22] [23]. Job satisfaction is defined as a favorable or positive state of emotion according to the evaluation of one's job or experience [24] [25]. Betty \& Schnier (1981) further defined job satisfaction as a pleasant emotional state obtained by workers performing their jobs by believing that they provide what they need for work with positive emotions that arise when evaluating jobs or job experiences [26]. According to previous studies, the higher the employee's satisfaction with the work environment, the higher the intention to remain in the organization where they are working [27]. Therefore, if the teacher's job satisfaction is high, it can be predicted that the residual intention will increase.

As a teacher variable, the recognition of professionalism can be defined as the knowledge and skills that a childcare teacher must possess to provide high quality of childcare. According to studies related to the professionalism perception of childcare teachers, the actual performance of childcare teachers as professionals is reported to vary depending on how much the childcare teachers perceive their professionalism [28]. In line with this, studies related to the recognition of the childcare teacher's professionalism as a variable explaining the intention of the childcare teacher to turnover have been actively conducted [29]. Professionalism can be measured through the knowledge and skills that a childcare teacher must possess in order to provide high quality of childcare [30]. It has been reported that the more childcare teachers recognize their professionalism, the lower the turnover intention is [15] [31]. Therefore, if the professionalism perception of the childcare teacher is high, the intention to stay to work more in the childcare center will be higher.

The intention to stay is an important variable to be dealt with in the study of teachers [32], as this section argued. However, there are no prior studies on the intention of the childcare teacher to remain. Existing studies closest to this topic are those that deal with turnover intention [31] [33]. Therefore, it would be logical to examine how the job satisfaction and professionalism of perception of childcare teachers affect the intention to stay. The results of this study are intended to assist in providing basic data for finding ways to increase the intention to stay of childcare teachers. Empirically and theoretically, this study will help enrich existing research in teacher education and development.

The specific research questions of this study are as follows:

Research Question 1: What is the relationship between childcare teacher's job satisfaction, professionalism perception and the intention to stay?

Research Question 2: What is the effect of job satisfaction and professionalism perception of childcare teachers on the intention to stay?

\section{Research Method}

\subsection{Method and Procedure of Sampling Subjects}

The subjects of this study were surveyed from November 3 to November 25, 2019. The subjects include 280 childcare teachers working in childcare centers located in Seoul and Gyeonggi-do, South Korea. A total of 245 data were used for the final analysis, with 11 copies being unsuccessful responses or missing values among the 256 questions collected. The demographic characteristics of the subjects are shown in Table 1. 
$41.2 \%$ of the surveyed participants are in their $40 \mathrm{~s}$, and $49.8 \%$ have a highest educational attainment of 2-3 years college graduation. Education experience of over 10 years was $32.2 \%$, and private nurseries were $47.8 \%$ for working institutions. As for the position, homeroom teachers comprise $66.9 \%$ of the total sample.

\subsection{Measurement Instruments}

\subsubsection{Job Satisfaction}

To measure job satisfaction, a Korean Childcare Teacher's Job Satisfaction Scale: K-CTJSS [34] was used. The sub-factors are the facility operation method of the manager (11 questions), social recognition (8 questions), work environment and welfare (6 questions), workload and time management (6 questions), relationship with peer teachers (5 questions), and relationship with parents (4 questions). The questionnaire consists of 40 questions. The 5-point Likert scale was used for the measurement. A high score means that the job satisfaction of the childcare teacher is high. In this study, the reliability Cronbach' $\alpha$ is the facility operation method or the manager .868 social recognition .960 , work environment and welfare .922 , workload and time management .750 , relationship with peer teachers .759 , relationship with parents. 878 , and total .942 .

\subsubsection{Professionalism Perception}

Wang's [35] Current Status and Self-Desire for Professional Competence, which was likewise used by Jeong [36], was used for measuring childcare teachers' professionalism perception. The sub-factors are composed of 30 questions: teaching ability (7 questions), operational management skills (6 questions), communication skills (9 questions), professional development ability (3 questions), and childcare protection skills (5 questions). The measurement used a 5-point Likert scale, which means that the higher the score, the higher the professionalism as a childcare teacher. Reliability Cronbach' $\alpha$ in this study was .91 for teaching ability, .89 for operational management ability, .90 for communication ability, .84 for professional development ability, and .85 for childcare protection and total .94 .

Table 1. Demographic characteristics of the sample

\begin{tabular}{|c|c|c|c|}
\hline \multicolumn{2}{|c|}{ Variables } & $\mathrm{N}$ & $\%$ \\
\hline \multirow{4}{*}{ Age(yr) } & $20 \mathrm{~s}$ & 57 & 23.3 \\
\hline & $30 \mathrm{~s}$ & 60 & 24.5 \\
\hline & $40 \mathrm{~s}$ & 101 & 41.2 \\
\hline & $50 \mathrm{~s}$ & 27 & 11.0 \\
\hline \multirow{4}{*}{ Education level } & High school & 53 & 21.6 \\
\hline & College(2 3yrs) & 122 & 49.8 \\
\hline & University(4yrs) & 57 & 23.3 \\
\hline & Graduate school & 13 & 5.3 \\
\hline \multirow{4}{*}{ Teaching experience(yr) } & 1 3yrs & 52 & 21.2 \\
\hline & 4-6yrs & 37 & 15.1 \\
\hline & 7-9yrs & 77 & 31.4 \\
\hline & Over 10yrs & 79 & 32.2 \\
\hline \multirow{5}{*}{ Type of childcare center } & Home & 98 & 40.0 \\
\hline & Private & 117 & 47.8 \\
\hline & Public & 15 & 6.1 \\
\hline & Work & 9 & 3.7 \\
\hline & Corporate & 6 & 2.4 \\
\hline \multirow{6}{*}{ Position } & Homeroom teacher & 164 & 66.9 \\
\hline & Head teacher & 27 & 11.0 \\
\hline & Vice-director & 10 & 4.1 \\
\hline & Director & 23 & 9.4 \\
\hline & Assistant teacher & 21 & 8.6 \\
\hline & Total & 245 & 100 \\
\hline
\end{tabular}




\subsubsection{The Intention to Stay}

To measure the intention to stay of childcare teachers, the study's questionnaire was developed based on the research of Mohanachandran \& Govindarajo [37], Iverson [38], Torquati, Raikes, \& Huddleston-Casas [39], and Graham [40]. The questions consisted of 6 questions. For the measurement, the 5-point Likert scale was used. The higher the computed score is, the higher the intention to stay of the childcare teachers. In this study, the reliability Cronbach' $\alpha$ was .81 .

\subsection{Analysis}

The data collected in this study were analyzed using SPSS 23.0. Technical statistical treatments were used to identify the general characteristics of the study subjects. To find the reliability of each measurement tool, a reliability coefficient was calculated. Pearson correlation analysis was performed to examine the relationship of each variable. Hierarchical regression analysis was employed to identify the effect of job satisfaction and professionalism perception on intention to stay.

\section{Result}

\subsection{Technical Statistics of Variables}

Table 2 shows the technical statistics of the variables. The average of job satisfaction of the study subjects was $3.66 \pm .49$ points, and the average of the sub-factors was $4.02 \pm .62$ of work environment and welfare, $3.91 \pm .75$ of social recognition, $3.90 \pm .66$ of relationship with parents, $3.68 \pm .61$ of workload and time management, $3.42 \pm .61$ of relationship with peer teachers, $3.14 \pm .68$ of facility operation method of the manager. The average of professionalism perception was $3.21 \pm .48$ points, and the average for each sub-factor was $3.26 \pm .52$ for communication skills, $3.21 \pm .54$ for childcare protection ability, $3.19 \pm .54$ for operation management ability, 3.18 \pm .49 for teaching ability, and professional development ability $3.18 \pm .59$. The mean of intention to stay was 2.25 \pm .74 points.

Table 2. Technical Statistics of Variables

\begin{tabular}{|l|c|c|}
\hline Variables & M & SE \\
\hline Job Satisfaction & 3.66 & .49 \\
\hline Social Recognition & 3.91 & .75 \\
\hline Facility Operation Method of the Manager & 3.14 & .68 \\
\hline Relationship with Peer Teachers & 3.42 & .60 \\
\hline Workload and Time Management & 3.68 & .61 \\
\hline Work Environment and Welfare & 4.02 & .62 \\
\hline Professionalism of Perception & 3.21 & .48 \\
\hline Teaching Ability & 3.18 & .49 \\
\hline Operation Management Ability & 3.19 & .54 \\
\hline Communication Skills & 3.26 & .52 \\
\hline Professional Development Ability & 3.18 & .59 \\
\hline Childcare Protection Ability & 3.21 & .54 \\
\hline Intention to Stay & 2.25 & .74 \\
\hline
\end{tabular}

\subsection{Correlation between Job Satisfaction, Professionalism Perception, and the Intention to Stay}

Table 3 shows the results of the correlation between job satisfaction, professionalism, and the intention to stay. Job satisfaction showed a significant positive correlation with professionalism perception $(\mathrm{r}=.141, \mathrm{p}<.05)$ and intention to stay $(\mathrm{r}=.416, \mathrm{p}<.001)$, and professionalism perception with intention to stay $(r=.606, p<.001)$.

Table 3. Correlation of Variables

\begin{tabular}{|l|c|c|c|}
\hline & 1 & 2 & 3 \\
\hline 1. Job Satisfaction & 1 & & \\
\hline 2. Professionalism Perception & $.14^{*}$ & 1 & \\
\hline 3. Intention to Stay & $.42^{* * *}$ & $.61^{* * *}$ & 1 \\
\hline${ }^{* * * *} \mathrm{p}<.001,{ }^{*} \mathrm{p}<.05$ & &
\end{tabular}

Table 4. Correlation between Sub-factors of Variables

\begin{tabular}{|c|c|c|c|c|c|c|c|c|c|c|c|c|}
\hline & SR & FO & RT & $\mathrm{RP}$ & WT & WE & TA & $\mathrm{OA}$ & CS & PA & CA & IS \\
\hline SR & 1 & & & & & & & & & & & \\
\hline FO & $.41^{* * * *}$ & 1 & & & & & & & & & & \\
\hline RT & $.36 * * *$ & $.50 * * *$ & 1 & & & & & & & & & \\
\hline $\mathrm{RP}$ & $.56^{* * *}$ & $.41 * * *$ & $.59 * * *$ & 1 & & & & & & & & \\
\hline WT & $.30 * * *$ & $.17^{* *}$ & $.43^{* * *}$ & $.34 * * *$ & 1 & & & & & & & \\
\hline WE & $.56 * * *$ & $39 * * *$ & $.32 * * *$ & $.58 * * *$ & $.33 * * *$ & 1 & & & & & & \\
\hline TA & .05 & $.20 * *$ & .06 & .08 & .04 & .08 & 1 & & & & & \\
\hline $\mathrm{OA}$ & .04 & $.17^{* *}$ & .07 & .07 & .01 & .07 & $.58 * * *$ & 1 & & & & \\
\hline CS & .11 & $.19^{* *}$ & .13 & .12 & -.02 & .10 & $.47 * * *$ & $.41^{* * * *}$ & 1 & & & \\
\hline PA & .04 & $.15^{*}$ & .08 & .07 & .02 & .06 & $.49 * * *$ & $.33 * * *$ & $.49 * * *$ & 1 & & \\
\hline CA & .08 & $.16^{*}$ & .09 & .11 & -.00 & .06 & $.42 * * *$ & $.35^{* * *}$ & $.54 * * *$ & $.51^{* * * *}$ & 1 & \\
\hline IS & $.34 * * *$ & $.36 * * *$ & $.33 * * *$ & $.31^{* * *}$ & $.16^{*}$ & $.29 * * *$ & $.52 * * *$ & $.45^{* * *}$ & $.49 * * *$ & $.42 * * *$ & $.41 * * *$ & 1 \\
\hline
\end{tabular}

${ }^{* * *} \mathrm{p}<.001, \stackrel{* *}{\mathrm{p}}<.01, \stackrel{*}{\mathrm{p}}<.05$

Note. Job satisfaction (SR: social recognition, FO: facility operation method of the manager, RT: relationship with peer teachers, RP: relationship with parents, WT: workload and time management, WE: work environment and welfare), professionalism of perception (TA: teaching ability, OA: operation management ability, CS: communication skills, PA: professional development ability, CA: childcare protection ability), IS: Intention to Stay 


\subsection{The Effects of Job Satisfaction and Professionalism Perception on the Intention to Stay}

Model 1 was statistically significant $(F=9.441, p<.001)$ as a result of hierarchical regression analysis to examine the effect of childcare teacher's job satisfaction and professionalism perception on intention to stay. The explanatory power of satisfaction was $19.2 \%$. Among the sub-factors of job satisfaction, social recognition $(\beta=.20$, $\mathrm{p}<.05)$, facility operation method of the manager $(\beta=.19$, $\mathrm{p}<.01)$, relationship with peer teachers $(\beta=.17, \mathrm{p}<.05)$ were found to have a significant positive effect on the intention to stay (Table 5).

Model 2 was also statistically significant $(\mathrm{F}=21.610$, $\mathrm{p}$ $<.001$ ). $50.5 \%$ of job satisfaction and professionalism perception were explained. Among the sub-factors of professional recognition, operational management ability $(\beta=.30, \mathrm{p}<.01)$ and communication skill $(\beta=.24, \mathrm{p}<.05)$ were found to have a significant positive effect on the intention to stay (Table 6).

Table 5. The Effects of Job Satisfaction on the Intention to Stay (Model1)

\begin{tabular}{|c|c|c|c|c|c|c|c|}
\hline & Variables & B & SE & $\beta$ & $\mathrm{t}$ & $\mathrm{p}$ & VIF \\
\hline \multirow{8}{*}{ Model1 } & Constant & .12 & .36 & & .34 & .732 & \\
\hline & SR & .20 & .10 & .20 & 2.00 & .047 & 2.883 \\
\hline & FO & .21 & .08 & .19 & 2.66 & .008 & 1.490 \\
\hline & RT & .21 & .10 & .17 & 2.08 & .039 & 1.994 \\
\hline & $\mathrm{RP}$ & -.01 & .10 & -.10 & -.11 & .912 & 2.445 \\
\hline & WT & -.01 & .08 & -.01 & -.14 & .889 & 1.310 \\
\hline & WE & .02 & .11 & .02 & .19 & .846 & 2.471 \\
\hline & \multicolumn{7}{|c|}{$\mathrm{F}=9.411, \mathrm{p}<.001, \mathrm{R}^{2}=.192$, Adj $\mathrm{R}^{2}=.172$} \\
\hline
\end{tabular}

Note. Job satisfaction (SR: social recognition, FO: facility operation method of the manager, RT: relationship with peer teachers, RP: relationship with parents, WT: workload and time management, WE: work environment and welfare)

Table 6. The Effects of Job Satisfaction and Professionalism Perception on the Intention to Stay (Model2)

\begin{tabular}{|c|c|c|c|c|c|c|c|}
\hline & Variables & B & SE & $\beta$ & $\mathrm{t}$ & $\mathrm{p}$ & VIF \\
\hline \multirow{13}{*}{ Model2 } & Constant & -2.21 & .35 & & -6.33 & .000 & \\
\hline & SR & .23 & .08 & .23 & 2.92 & .004 & 2.922 \\
\hline & $\mathrm{FO}$ & .09 & .06 & .09 & 1.48 & .139 & 1.551 \\
\hline & $\mathrm{RT}$ & .21 & .08 & .17 & 2.56 & .011 & 2.041 \\
\hline & $\mathrm{RP}$ & -.04 & .08 & -.03 & -.45 & .653 & 2.460 \\
\hline & WT & .02 & .07 & .01 & .25 & .805 & 1.349 \\
\hline & WE & -.01 & .09 & -.01 & -.11 & .909 & 2.485 \\
\hline & TA & .01 & .14 & .01 & .11 & .915 & 3.823 \\
\hline & $\mathrm{OA}$ & .42 & .14 & .30 & 3.01 & .003 & 4.785 \\
\hline & CS & .33 & .15 & .24 & 2.29 & .023 & 4.947 \\
\hline & PA & .11 & .11 & .09 & 1.02 & .308 & 3.430 \\
\hline & CA & -.04 & .13 & -.03 & -.27 & .787 & 4.245 \\
\hline & \multicolumn{7}{|c|}{$\mathrm{F}=21.610, \mathrm{p}<.001, \mathrm{R} 2=.505$, Adj $\mathrm{R} 2=.482$} \\
\hline
\end{tabular}

Note. Job satisfaction (SR: social recognition, FO: facility operation method of the manager, RT: relationship with peer teachers, RP: relationship with parents, WT: workload and time management, WE: work environment and welfare), professionalism of perception (TA: teaching ability, OA: operation management ability, CS: communication skills, PA: professional development ability, CA: childcare protection ability), IS: Intention to Stay 


\section{Discussions and Results}

This study was conducted to assist primarily in finding ways to increase the intention to stay of childcare teachers by examining the effects of job satisfaction and professionalism perception on the intention to stay. The discussion of the results is as follows.

First, there was a significant positive correlation between job satisfaction and professionalism perception, job satisfaction and intention to stay. In addition, there was a significant positive correlation between job satisfaction and professionalism perception. Other studies reflect the same results. In the studies of Mrayyan [41] and De Oliveira, Natividade, De Assis, \& Mambrini [42], results showed a statistically significant correlation between job satisfaction and intention to stay. In the study of Kim et al. [31], there was a significant negative correlation between the professionalism perception and turnover intention of the childcare teacher, and it can be said to be in the same context as the result that there was a significant positive correlation between professionalism perception and job satisfaction. Studies in other occupational groups have reported that the higher the job satisfaction of hotel workers, the higher the intention to stay [43]. In addition, studies of nurses have reported that the higher the professional value of a nurse, the higher the residual intention [44]. Therefore, the results of this study support that job satisfaction and professionalism perception should be considered when looking for ways to increase the intention to stay of childcare teachers.

Second, job satisfaction and professionalism had a significant positive effect on the intention to stay. This is in the same context as the results of a study by Youcef, Ahmed, \& Ahmed [21] that job satisfaction affects the intention to stay through organizational commitment. A study by Radford \& Meissner [20] agrees with the finding that job satisfaction had an effect on intention to stay. In this study, social recognition, operation method of the manager, relationship with peer teachers were found to be factors affecting intention to stay. Therefore, in order to increase the intention to stay of childcare teachers, it is vital to increase social awareness of childcare teachers and maintain a positive relationship between managers and peer teachers.

It is difficult to find prior studies on professional perception and the intention to stay. However, studies that considered turnover intention as a variable related to intention to stay report that professionalism perception has a significant effect on turnover intention [31], [45]. Huang \& Cho (2010) emphasized that professional development should be considered to increase retention of childcare teachers [46]. These studies fall under the same purview as this study. In other words, it can be inferred that if childcare teachers are satisfied with the job and have high-level of professionalism, they will want to work more in the childcare center.
For childcare teachers, this variable is related to the quality of childcare. The way to increase the intention to stay of childcare teacher is a critical factor in maintaining the quality of childcare in childcare centers. Therefore, in order to increase the intention to stay of childcare teachers, it is necessary to create a working environment that pleases the childcare teachers. If professionalism as a teacher is increased through consideration of rehabilitation or re-education of the childcare teacher, the intention to stay of the childcare teacher to remain will increase. Based on these results, administrative support is needed to increase the job satisfaction of childcare teachers. In addition, a variety of teacher education development programs are needed to enhance professionalism perception.

Finally, suggestions for limitations and follow-up studies in this study are as follows. First, the relationship between job satisfaction, professionalism perception, and the intention to stay of childcare teachers was examined, but it is necessary to study the differences according to demographic variables of childcare teachers in subsequent studies. Second, since this study was conducted through a self-written questionnaire, other studies that use different methods, such as in-depth interviews, should be conducted in order to understand the intention to stay of childcare teacher.

\section{REFERENCES}

[1] Lee, C. J. (2018). A Study on the Process and Effectiveness of Childcare Policy Extension in Korea: Focusing on the Impact on Defamilialization of Childcare Burden. Doctoral dissertation, Seoul National University.

[2] Ministry of Health and Welfare (2019), Childcare Statistics. Sejong: Ministry of Health and Welfare.

[3] Lee, S. I. (2017), The Relationship between Quality of Relational Working Environment and Emotional Burnout: Moderating Effect of Emotional Regulation, Master' thesis, Kyung Hee University.

[4] Choi, Y. K., Lee, Y. J., Kim, S. H., \& Na, J. H. (2012), Consideration of the Hours of Use of Child Care Support Institutions from the Viewpoint of Child Development-focusing on the Stress Hormone Survey, Seoul: Korea Institute of Child Care and Education.

[5] Lin, Y. \& Magnuson, K. A. (2018), Classroom Quality and Children's Academic Skills in Child Care Centers: Understanding the Role of Teacher Qualifications, Early Childhood Research Quarterly, 42(1): 215-227.

[6] Price, J. L., \& Mueller, C. W. (1981), A Causal Model of Turnover for Nurses, Academy of Management Journal, 34: 534-565.

[7] Redditt, J., Gregory, A. M., \& Ro, H. (2017), An Examination of Organizational Commitment and Intention to Stay in the Timeshare Industry: Variations Across 
Generations in the Workplace, International Journal of Hospitality \& Tourism Administration, 20(2): 206-225.

[8] Torquati, J. Raikes, H. \& Huddleston-Casas, G. A. (2007). Teacher education, motivation, compensation, workplace support, and links to quality of center-based child care and teachers' intention to stay in the early childhood profession. Early Childhood Research Quarterly, 22(2), 261-275.

[9] McConnel III, J. R. (2017), A model for uderstanding teachers' intentions to remain in STEM education. International Journal of STEM Education, 4(7), 1-21.

[10] Jung, W. S. (2019). The effects of a principal's coaching leadership, organizational culture on early childhood teacher's job satisfaction, turnover intention. master thesis, Kwangju Women's University.

[11] Cho, S., Johanson, M. M., \& Guchait, P. (2009). Employees Intent to Leave: A Comparison of Determinants of Intent to Leave Versus Intent to Stay, International Journal of Hospitality Management, 28(3): 374-381.

[12] Jeong, W. S., \& Oh, J. Y. (2020). The Effect of Director's Coaching Leadership and Organizational Culture in Early Childhood Education Institutions on Teachers' Job Satisfaction and Turnover Intention, Open Early Childhood Education Research, 25(1): 161-189.

[13] Choe, H. S. (2017). The Effects of Resilience, Job Satisfaction, and Burnout on Intention to Leave of Infant Teachers in Korea. Journal of Early Childhood Education \& Educare Welfare, 21(3): 129-149.

[14] Kwon, H. S., \& Kwon, S. M. (2017), The Effects of a Kindergarten Teacher's Empowerment, Life Stance and Teacher Efficacy on Turnover Intentions - the Mediated Effects of Burnout and Social Support, Open Early Childhood Education Research, 22(1): 379-401.

[15] Cha, S. J. (2019), The Effect of the Interpersonal Stress and Childcare Teacher's Perception of Professionalism on the Turnover Intention, Master thesis, Yonsei University.

[16] Grant, A. A., Jeon, L., \& Buettner, C. K. (2019), Chaos and Commitment in the Early Childhood Education Classroom: Direct and Indirect Associations through Teaching Efficacy, Teaching and Teacher Education, 81(2019): 50-60.

[17] Appel-Drazin, K. (2016). Work environment, leadership, and teacher retention in early childhood education. Unpublished doctoral dissertation, Olivet Nazarene University, IL, USA.

[18] Singh, K., \& Billingsley, B. S. (1996), Intent to Stay in Teaching, Remedial and Special Education, 17(1): 37-47.

[19] Sedivy-Benton, A. L., \& Boden McGill, C. J. (2012). Significant Factors for Teachers' Intentions to Stay or Leave the Profession: Teacher Influence on School, Perception of Control, and Perceived Support. National Teacher Education Journal, 5(2): 99.

[20] Radford, K., \& Meissner, E., (2017), Job Satisfaction and Intention to Stay within Community and Residential Aged Care Employees. Australasian Journal on Ageing, 36(3), E1-E6.

[21] Youcef, S., Ahmed, S. S., \& Ahmed, B. (2016), The Impact of Job Satisfaction on Turnover Intention by the Existence of Organizational Commitment, and Intent to Stay as
Intermediates Variables Using Approach PLS in Sample Worker Department of Transport Saida, Management, 6(6): 198-202.

[22] Lee, J. Y., \& Lee, Y, N. (2020). The mediation effects of organizational commitment in the relationship of between organizational culture and the childcare teachers' intention to stay. Korean Journal of Early Childhood Education, 40(4), 263-289.

[23] Billingsley, B., \& Cross, L. H. (1992). Predictors of commitment, job satisfaction, and intent to stay in teaching: A comparison of general and special educators. The Journal of Special Education, 25(4), 453-471.

[24] Schneider, B., \& Snyder, R. A. (1975). Some relationships between job satisfaction and organization climate. J. Appl. Psychol, 60, 318

[25] Locke, E. (1976). The nature and cause of job satisfaction. In M. D. Dunnette (ed.), Handbook of industrial and organizational psychology, 1297-1349. (Chicago, IL: Rand McNally)

[26] Betty, R. W., \& Schnier, C. E. (1981). Personnel Administration: An Experimental Skill Building Approach, 2nd ed, New York, NY: Addison-Wesley Publishing Company

[27] Bangwal, D., \& Tiwri, P. (2019). Workplace environment, employee satisfaction and intent to stay. Iternational Journal of Contemporary Hospitality Management, 31(1), 268-284.

[28] Hargreaves, A. (2000), Four Ages of Professionalism and Professional Learning, Teachers and Teaching: Theory and Practice, 6(2): 151-182.

[29] Chung, S. A., \& Cho, D. Y. (2013). A study of analyzing the need of early childhood teachers` job competency. Korean Journal of Early Childhood Education, 33(1), 299-321.

[30] Jin, K. M. (2017). Association between childcare teachers' perceived work environment, professionalism and turnover intention, master thesis, Kyunghee University.

[31] Kim, M. S., S. J. Kim, H. O. Kang, \& A. R. Jung (2018), The Structural Relationship between Child Care Teachers' Perception of Job Satisfaction, Professionalism, Organizational Climate, and Turnover Intention, Early Childhood Education Research, 38(1): 391-415.

[32] Battle, A., \& Looey, L. (2014). Teachers' intentions to stay in teaching: The role of values ad knowledge of adolescent development. Education, 134(3), 369-379.

[33] Cassidy, D. J., Lower, J. K., Kintner-Duffy, V. L., Hegde, A. V., \& Shim, J. (2011). The day-today reality of teacher turnover in preschool classrooms: An analysis of classroom context and teacher, director, and parent perspectives. Journal of Research in Childhood Education, 25 (1), 1-23.

[34] Cho, S. Y., Baik, E. J., Kim, H. G., Kwon, Y. H., \& Chung, J. N.(2011). Study for Validation of the Korean Childcare Teacher's Job Satisfaction Scale (K-CTJSS). Journal of Korean Home Management Association, 29(2), 1-12.

[35] Wang, H. (2005). Early childhood educator's perceptions of professional competence in preschool setting. Doctoral dissertation. Pennsylvania: Pennsylvania State University.

[36] Jeong, A. R. (2016). The effects of the chlidcare center's 
organizational climate on early childhood teacher's perception of professionalism. Master thesis, Yonsei University.

[37] Mohanachandran, D. K., \& Govindarajo, N. S. (2014). Instrument development 'intention to stay instrument'. Asian Social Science, 10(12), 1-22.

[38] Iverson, R. D. (1992). Employee intent to stay: An empirical test of a revision of the Price and Mueller model. Unpublished doctoral dissertation, University of Iowa, Ames.

[39] Torquati, J. C., Raikes, H., \& Huddleston-Casas, C. A. (2007), Teacher education, motivation, compensation, workplace support, and links to quality of center-based child care and teachers' intention to stay in the early childhood profession. Early Childhood Research Quarterly, 22(2), 261-275.

[40] Graham, K. (2012). Development and validation of a measure of intention to stay in academia for physician assistant faculty. Journal of Physician Assistant Education, 26(1), 10-18.

[41] Mrayyan, M. (2007), Jordanian Nurses' Job Satisfaction and
Intent to Stay: Comparing Teaching and Non-teaching Hospitals, Journal of Professional Nursing, 23(3): 125-136.

[42] De Oliveira, M. Z., Natividade, J. C. , de Assis, R. S. , \& Mambrini, N. S. B. (2019), Performance, Satisfaction and Intention to Remain in Organizations: Individual to Contextual Predictors, Trend in Psychology, 27(2): 549-567.

[43] Yoo, H. J., \& Kim, K. A. (2019). The effect of hotel internal marketing and job satisfaction on workers' intention to stay: Focused on the moderating effects of job autonomy. International Journal of Tourism and Hospitality Research, 33(9), 41-56.

[44] Yarbrough, S., Martin, P., Alfred, D., \& McNeill, C. (2017). Professional values, job satisfaction, career development, and intent to stay. Nursing Ethics, 24(6), 675-685.

[45] Cho, N. Y., \& Moon, J. W. (2018). The Effect of the Ecological System Factors on Childcare Teachers' Turnover Intention, Early Childhood Education Child Welfare Research, 22(3): 67-89.

[46] Huang, D., \& Cho, J. (2010). Using professional development to enhance staff retention. Afterschool Matters, 2010(Fall), 9-16. 